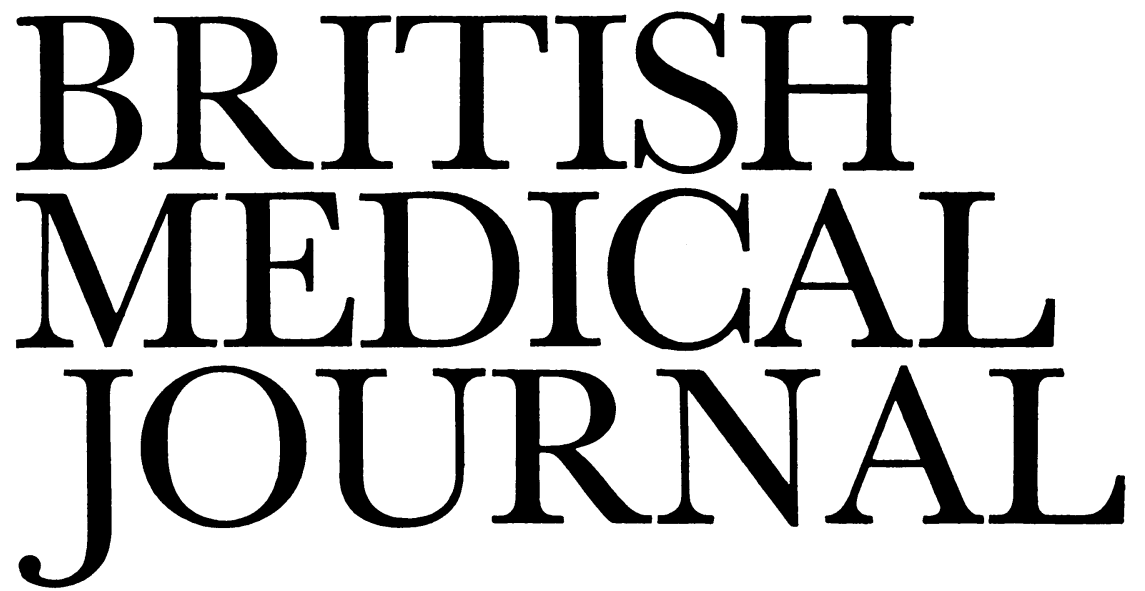

LONDON, SATURDAY 18 APRIL 1981

\title{
Treatment of ulcerative colitis
}

The management of patients with ulcerative colitis is centred on prompt treatment of the exacerbations backed up by maintenance therapy intended to prolong the remissions for as long as possible. Since the aetiology of ulcerative colitis is unknown these treatments have remained empirical. Controlled trials have proved the efficacy of both sulphasalazine and corticosteroids, ${ }^{1-3}$ but the optimum regimens have to take account of the wide clinical variability of the disease. The severity of exacerbations is usually graded as mild, moderate, or severe. ${ }^{4}$

Mild disease may be defined as diarrhoea with four or fewer bowel motions daily, only small amounts of visible blood in the stools, and no serious constitutional upset. In such cases sulphasalazine $1 \mathrm{~g}$ three times a day may be sufficient treatment. Nausea and headache, which are frequent side effects of sulphasalazine, are less common if the initial dosage is low with a gradual build-up to $3 \mathrm{~g}$, and enteric-coated tablets may also be less upsetting. The alternative is treatment with prednisone $20 \mathrm{mg}$ a day in divided doses either alone or combined with a steroid enema.

Patients with moderate acute attacks have pronounced bloody diarrhoea and severe inflammatory changes seen on sigmoidoscopy but no major constitutional upset. Treatment requires higher doses: prednisone $0 \cdot 25-0.75 \mathrm{mg} / \mathrm{kg}$ body weight or sulphasalazine $4 \mathrm{~g}$ a day as well as steroid enemas. Some of these patients feel ill and may have systemic manifestations of the disease such as arthritis, conjunctivitis, uveitis, and erythema nodosum. Admission to hospital for bed rest may be necessary. Once the systemic features of the illness have improved treatment with steroids may be gradually withdrawn.

In severe attacks there are six or more bowel motions a day containing obvious blood and mucus, with fever, tachycardia, anaemia, hypoalbuminaemia, and a high erythrocyte sedimentation rate. Such attacks require intensive medical care with immediate admission to hospital. Progress should be monitored daily with abdominal radiographs. Treatment will require intravenous prednisolone 21-phosphate $60 \mathrm{mg}$ a day in divided doses, steroid enemas three times a day (or a rectal hydrocortisone drip), sulphasalazine $4 \mathrm{~g}$ a day in divided doses, and replacement of fluids and electrolytes, blood, and albumin. Total parenteral nutrition may be helpful, ${ }^{5}$ though its value has been challenged. ${ }^{6}$
Most patients improve on this regimen and after five days may be switched to treatment with steroids by mouth. A small minority do not improve or develop toxic megacolon, peritonitis, or a massive haemorrhage and emergency colectomy may be unavoidable. Acute exacerbations occurring during pregnancy should be treated on the same lines as in other patients. ${ }^{7}$

Topical steroids have a local effect on the mucosa in acute colitis. They may be given as suppositories or enemas either as liquid or as foam. Suppositories are effective in proctitis. ${ }^{8}$ Steroid enemas may be given as a slow drip or as a rapid bolus. The volume required varies with the extent of the colitis; the amount may be estimated by adding barium to the enema and monitoring its spread by $x$-ray examination to ensure contact with the inflamed mucosa. ${ }^{9}$ Rectal hydrocortisone foam is as effective as enemas and preferable for most patients in the treatment of active proximal colitis. ${ }^{10}$

How may remissions best be prolonged? Corticosteroids are of no value, but sulphasalazine, $1 \mathrm{~g}$ twice a day, reduces the relapse rate. ${ }^{11}$ Higher doses are more effective but will increase the incidence of side effects. ${ }^{12}$ Maintenance treatment should be given for one year after an exacerbation, ${ }^{13}$ and some gastroenterologists recommend that it should be continued indefinitely, unless contraindicated by side effects. ${ }^{14}$ About $70 \%$ of the sulphasalazine reaches the colon intact, where the azobond is split by bacteria. Most of 5-aminosalicylic acid is excreted in the stool but the sulphapyridine is absorbed and metabolised by acetylation, by the formation of other conjugates, and by hydroxylation. The side effects of sulphasalazine (which include reversible male sterility ${ }^{15}$ ) are commoner in slow than fast acetylators. ${ }^{16}$ Exactly how the drug acts remains uncertain, but its efficacy may be due to the concurrent action of the three compounds on the acute inflammatory response. ${ }^{17} \mathrm{~A}$ study in which sulphasalazine, 5-aminosalicylic acid, and sulphapyridine were given as retention enemas to patients with colitis showed that the first two induced improvement whereas the last had no effect. ${ }^{18}$ Sulphasalazine and 5aminosalicylic acid (but not sulphapyridine) inhibit prostaglandin synthetase, ${ }^{19}$ and amounts of this enzyme are raised in rectal tissue obtained by biopsy from patients with active colitis. ${ }^{20}$ When 5 -aminosalicylic acid is given by mouth it is absorbed in the upper intestinal tract. Further studies on other 
substituted salicylates may lead to the development of an effective oral agent that is not associated with the side effects of sulphapyridine. ${ }^{21}$

Two other drugs have been investigated as possible treatments: azathioprine and disodium cromoglycate. Azathioprine ( $2.5 \mathrm{mg}$ per $\mathrm{kg}$ body weight) has been added to corticosteroid treatment of acute ulcerative colitis but little benefit was observed. Azathioprine may, however, be of marginal use as a prophylactic treatment in patients who relapse frequently. ${ }^{22}$ As a supplementary treatment to patients with acute colitis unresponsive to steroids or sulphasalazine disodium cromoglycate was of no value in inducing a remission ${ }^{23}$; as a maintenance treatment disodium cromoglycate was less effective than sulphasalazine and no better than placebo. ${ }^{24}$ For the time being, then, despite the high incidence of dose-related side effects, sulphasalazine remains the drug of choice for the prolonged treatment of patients with ulcerative colitis in remission.

${ }^{1}$ Matts SGF. Local treatment of ulcerative colitis with prednisolone 21phosphate enemata. Lancet $1960 ; \mathrm{i}: 517-9$.

2 Lennard-Jones JE, Longmore AJ, Newell AC, Wilson CWE, Jones FA. An assessment of prednisone, Salazopyrin, and topical hydrocortisone hemisuccinate used as out-patient treatment for ulcerative colitis. Gut $1960 ; 1: 217-22$.

${ }^{3}$ Baron JH, Connell AM, Lennard-Jones JE, Jones FA. Sulphasalazine and salicylazosulphadimidine in ulcerative colitis. Lancet 1962 ; i :1094-6.

4 Truelove SC. Ulcerative colitis. In: Harper PS, Muir FR, eds. Advanced medicine. Vol 15. Tunbridge Wells : Pitman Medical, 1979:246-51.

5 Truelove SC, Willoughby CP, Lee EG, Kettlewell MGW. Further experience in the treatment of severe attacks of ulcerative colitis. Lancet 1978; ii:1086-8.

6 Dickinson RJ, Ashton MG, Axon ATR, Smith RC, Yeung CK, Hill GL. Controlled trial of intravenous hyperalimentation and total bowel rest as an adjunct to the routine therapy of acute colitis. Gastroenterology 1980;79:1199-204.

7 Willoughby CP, Truelove SC. Ulcerative colitis and pregnancy. Gut 1980; $21: 469-74$.

8 Lennard-Jones JE, Baron JH, Connell AM, Jones FA. A double blind controlled trial of prednisolone-21-phosphate suppositories in the treatment of idiopathic proctitis. Gut $1962 ; 3: 207-10$.

- Swarbrick ET, Loose H, Lennard-Jones JE. Enema volume as an important factor in successful topical corticosteroid treatment of colitis. Proc $R$ Soc Med 1974;67:753-7.

${ }^{10}$ Ruddell WSJ, Dickinson RJ, Dixon ME, Axon ATR. Treatment of distal ulcerative colitis (proctosigmoiditis) in relapse. Comparison of hydrocortisone enemas and rectal hydrocortisone foam. Gut 1980;21:885-9.

11 Lennard-Jones JE, Connell AM, Baron JH, Jones FA. Controlled trial of sulphasalazine in maintenance therapy for ulcerative colitis. Lancet $1965 ; \mathrm{i}: 185-8$.

12 Khan AKA, Howes DT, Piris J, Truelove SC. Optimal dose of sulphasalazine for maintenance treatment of ulcerative colitis: interim results of a controlled therapeutic trial. Gut 1977;18:421.

13 Riis $P$, Anthonisen $P$, Wulff HR, Folkenborg O, Bonnevie O, Binder V. The prophylactic effect of salazosulfapyridine in ulcerative colitis during long-term treatment. A double-blind trial on patients asymptomatic for one year. Scand f Gastroenterol 1973;8:71-4.

14 Dissanayake AS, Truelove SC. A controlled therapeutic trial of long-term maintenance treatment of ulcerative colitis with sulphasalazine (Salazopyrin). Gut 1973;14:923-6.

15 Levi AJ, Fisher AM, Hughes L, Hendry WF. Male infertility due to sulphasalazine. Lancet 1979;ii :276-8.

16 Lennard-Jones JE, Powell-Tuck J. Drug treatment of inflammatory bowel disease. Clin Gastroenterol 1979;8:187-217.

17 Molin L, Stendahl O. The effect of sulfasalazine and its active components on human polymorphonuclear leukocyte function in relation to ulcerative colitis. Acta Med Scand 1979 ;206 :451-7.

18 Khan AKA, Piris J, Truelove SC. An experiment to determine the active therapeutic moiety of sulphasalazine. Lancet 1977 ;ii:892-5.

19 Gould SR, Lennard-Jones JE. Production of prostaglandins in ulcerative colitis and their inhibition by sulphasalazine. Gut 1976;17:828.

20 Harris DW, Swan CHJ. Increased synthesis of prostaglandins in ulcerative colitis. Lancet 1977 ;ii : 196 .

21 Willoughby CP, Piris J, Truelove SC. The effect of topical N-acetyl-5aminosalicylic acid in ulcerative colitis. Scand $\mathcal{F}$ Gastroenterol 1980;15 715-9.

22 Jewell DP, Truelove SC. Azathioprine in ulcerative colitis: final report on controlled therapeutic trial. $\mathrm{Br} M e d \mathcal{F} 1974 ;$ iv:627-30.

${ }^{23}$ Buckell NA, Gould SR, Day DW, Lennard-Jones JE, Edwards AM. Controlled trial of disodium cromoglycate in chronic persistent ulcerative colitis. Gut 1978;19:1140-3.

${ }^{24}$ Langman $M J$, Dronfield $M W$. Disodium cromoglycate maintenance treatment of ulcerative colitis. Acta Allergologica 1977:13, suppl:76-81.

\section{Psychiatry in the general hospital}

Twenty years ago Shepherd and others ${ }^{1}$ found that 38 of 100 consecutive medical outpatients at a London hospital had a psychiatric disability without any sign of physical disease. Twenty-one of the patients had neurotic reactions or personality difficulties and 17 had depression. Another 13 patients were both psychiatrically and physically ill. Many other examples could be quoted. More recently Maguire $e t a^{2}$ judged that 53 $(23 \%)$ of 230 consecutive medical admissions had a psychiatric illness-after those who had attempted suicide or who were too unwell to participate in the study had been excluded from the sample. Goldberg's ${ }^{3}$ general health questionnaire and the Standardised Psychiatric Interview ${ }^{4}$ were used to determine the presence of psychiatric illness, and diagnoses of depressive illness or anxiety state were made for 36 of the affected individuals. In 17 of this subgroup the mood disturbance seemed to represent an adverse psychological response to physical disease.

Yet despite this weight of evidence general and specialist physicians still show a high threshold of suspicion for formal psychiatric disorder. Brody ${ }^{5}$ has claimed that in medical outpatients in the United States interns and residents missed one-third of the psychiatric disturbances that were detected by means of the general health questionnaire. Physicians here are as reluctant to ask for a psychiatric opinion; in the two British surveys only one in 30 medical and surgical outpatients and one in 10 inpatients were examined by a psychiatrist.

Estimates of numbers vary from one study to another but the overall conclusions are consistent: many more patients are :assessed as having psychiatric disorders than are referred to psychiatrists. What are the explanations offered? The extent of psychiatric morbidity in general hospital populations may have been overestimated for methodological reasons; the organisation and quality of local psychiatric services may be inadequate to meet general medical demands; or most psychiatric disorders identified in these surveys may be too benign to give physicians cause to seek a psychiatric opinion.

A more realistic explanation is that many consultant physicians seem to be so sceptical about the effectiveness of psychiatric diagnosis and management that they resist referring patients to psychiatrists. Steinberg $e t a l^{6}$ have published the findings of a North American investigation that showed that attending physicians refused to accept their junior staffs' recommendations for psychiatric referrals in over half of a series of medical inpatients with "major emotional problems" related to their illness or treatment. In 30 of the 50 cases where there was resistance the physicians either minimised the relevance of psychiatric symptoms to the medical management or were unaware of the benefit that could have resulted to the patient from a psychiatric intervention. In a further 12 instances the physicians stated that a psychiatric consultation might make their patient angry or emotionally upset and so impair the doctor-patient relationship. Similar views are met? in Britain. Mezey and Kellett" sent a questionnaire on "reasons for not referring a patient to a psychiatrist" to all 106 nonpsychiatric clinical consultants who were on the staffs of six general hospitals in a defined area. Eighty-eight consultants completed the form and, of the 10 reasons given, the one that $\overline{2}$ influenced most of them (40) against a referral was the belief $\delta$ that the patient would dislike being referred to a psychiatrist. The next most common reason was that the patient would be put at some disadvantage by being labelled as a "mental case." . 